\title{
Longitudinal Relations Between Prosocial Television Content and Adolescents' Prosocial and Aggressive Behavior: The Mediating Role of Empathic Concern and Self-Regulation
}

\author{
Laura M. Padilla-Walker \\ Brigham Young University - Provo \\ Sarah M. Coyne \\ Brigham Young University - Provo, smcoyne@byu.edu \\ Kevin M. Collier \\ Brigham Young University - Provo \\ Matthew G. Nielson \\ Bollghi \\ Part of the Other Social and Behavioral Sciences Commons
}

\section{Original Publication Citation}

Padilla-Walker, L. M., Coyne, S. M., *Collier, K. M., \& *Nielson, M. G. (2015). Longitudinal relations between prosocial television content and adolescents' prosocial and aggressive behavior: The mediating role of empathic concern and self-regulation. Developmental Psychology, 51, 1317-1328.

\section{BYU ScholarsArchive Citation}

Padilla-Walker, Laura M.; Coyne, Sarah M.; Collier, Kevin M.; and Nielson, Matthew G., "Longitudinal Relations Between Prosocial Television Content and Adolescents' Prosocial and Aggressive Behavior: The Mediating Role of Empathic Concern and Self-Regulation" (2015). Faculty Publications. 4026.

https://scholarsarchive.byu.edu/facpub/4026

This Peer-Reviewed Article is brought to you for free and open access by BYU ScholarsArchive. It has been accepted for inclusion in Faculty Publications by an authorized administrator of BYU ScholarsArchive. For more information, please contact ellen_amatangelo@byu.edu. 


\title{
Longitudinal Relations Between Prosocial Television Content and Adolescents' Prosocial and Aggressive Behavior: The Mediating Role of Empathic Concern and Self-Regulation
}

\author{
Laura M. Padilla-Walker, Sarah M. Coyne, Kevin M. Collier, and Matthew G. Nielson \\ Brigham Young University
}

\begin{abstract}
The current study examined longitudinal cross-lagged associations between prosocial TV (content and time) and prosocial and aggressive behavior during adolescence, and explored the mediating role of empathic concern and self-regulation. Participants were 441 adolescents who reported on their 3 favorite TV shows at 2 time points, approximately 2 years apart ( $M$ age of child at Time $3=13.31, S D=1.06$; $52 \%$ female; $M$ age of child at Time $5=15.27, S D=1.06$ ). Results suggested that prosocial content at Time 3 was negatively associated with aggressive behavior 2 years later, and aggressive behavior at Time 3 was positively associated with aggressive content 2 years later. Results also suggested that prosocial behavior toward strangers at Time 3 was associated with both empathic concern and self-regulation at Time 4, which were in turn associated with prosocial and aggressive content at Time 5. Discussion focuses on the important role of behavior and prosocial personality on media selection during adolescence and the relevance of the target of prosocial behavior.
\end{abstract}

Keywords: media content, prosocial media, prosocial TV, TV content, adolescence

Over a thousand studies have focused on the effect of viewing media violence, and though some studies find no effect (e.g., Ferguson, San Miguel, \& Hartley, 2009), the vast majority reveal that viewing media violence is associated with increased aggressive behavior (e.g., Anderson et al., 2010; DeLisi et al., 2013; Gentile, Coyne, \& Walsh, 2011). Though the media shows many examples of behavior intended to harm others, it also portrays behavior intended to help others, or prosocial behavior (e.g., Smith et al., 2006). Compared with studies on media violence, the effects of viewing prosocial behavior in the media are relatively unknown, especially during adolescence when frequency of viewing TV and other mediums remains high, but relevant educational and prosocial programs are less frequent. It is possible that viewing prosocial behavior in the media may socialize adolescent behavior. Conversely, it is also possible that adolescents' prosocial behavior leads to a desire to view increased amounts of prosocial media. Accordingly, the current study examined longitudinal cross-lagged

This article was published Online First July 6, 2015.

Laura M. Padilla-Walker, Sarah M. Coyne, Kevin M. Collier, and Matthew G. Nielson, School of Family Life, Brigham Young University.

We thank the Family Studies Center at BYU, the School of Family Life, and the College of Family Home and Social Science at BYU, and we recognize the generous support of the many private donors who provided support for this project. We also thank those families who were willing to spend valuable hours with our team in interviews, and the many students who assisted in conducting the interviews. Finally, we would like to acknowledge Spencer James and Jeremy Yorgason for their careful and continuous input, advice, and knowledge.

Correspondence concerning this article should be addressed to Laura M. Padilla-Walker, 2097 JFSB, School of Family Life, Brigham Young University, Provo, UT 84602. E-mail: laura_walker@byu.edu associations between viewing prosocial behavior in the media and prosocial and aggressive behavior during adolescence.

\section{Prosocial Behavior}

Prosocial behavior is defined as voluntary behavior meant for the benefit of another (Eisenberg, Fabes, \& Spinrad, 2006), and is linked with a number of positive outcomes including success in school (Wentzel, 1993), high self-esteem (Caprara et al., 2000), and positive friendships (Laible, Carlo, \& Roesch, 2004). Prosocial behavior also protects individuals from negative outcomes including aggression (Laible et al., 2014), depression, delinquent behavior (Padilla-Walker, Carlo, \& Nielson, in press), and negative peer influence (Carlo et al., 2014). Despite the seemingly straightforward definition, the multidimensional nature of prosocial behavior means that the above outcomes may vary as a function of the type and target of prosocial behavior, and that media may differentially impact prosocial behavior toward different targets. For example, prosocial behavior has been shown to vary according to the relationship between the initiator and the target (or recipient) of the behavior (Amato, 1990; Eberly \& Montemayor, 1999; Padilla-Walker \& Christensen, 2011). People are most likely to help those they feel close to (Eisenberg, 1983) and more likely to help those they know over strangers (Amato, 1990). Further, people are prosocial in different ways and for different reasons when the target is a family member (there are even differences between helping mothers and fathers, see Eberly \& Montemayor, 1999) as compared with friends or strangers (Padilla-Walker \& Christensen, 2011). For example, prosocial behavior toward strangers is most strongly motivated by dispositional factors such as empathic concern. Dispositional factors are indicators of moral personality or identity, which is a consistent predictor of high-cost prosocial behavior (Hart, Atkins, \& Ford, 
1998; Padilla-Walker \& Fraser, 2014), and is often directed toward strangers in the form of community service or extended volunteering. In contrast, prosocial behavior toward family and friends is more often motivated by relationship-quality, norms, or desires to maintain the relationship (Padilla-Walker \& Christensen, 2011; Rusbult \& Agnew, 2010). Thus, it is possible that exposure to prosocial media could promote behavior toward one target but not another, or that prosocial behavior toward one target may promote the selection of prosocial media more than other targets. Given that the current study is assessing prosocial media content as it relates to dispositional factors (empathic concern and self-regulation), it is possible that prosocial behavior toward strangers will be more salient because it is more strongly influenced by these factors.

\section{Prosocial Media}

To our knowledge, there are only a handful of content analyses of prosocial behavior in the media compared with dozens on aggression in the media (e.g., Coyne, Callister, \& Robinson, 2010; National Television Violence Study, 1998). Early content analyses found that prosocial behavior does exist in the media (Lee, 1988; Potter \& Ware, 1989). The most comprehensive content analysis (involving 2,227 programs) found that children's programing had the most prosocial behavior compared with other programs $(78 \%$ of shows; 4.02 acts per hour), but this study defined prosocial behavior as altruistic "helping and/or sharing" (Smith et al., 2006).
To represent the multi-dimensionality of prosocial behavior, Padilla-Walker, Coyne, Fraser, and Stockdale (2013) analyzed multiple types of prosocial behavior in Disney animated films, including both verbal and physical types, as well as the target of the behavior. Findings suggested that prosocial behavior was extremely common in Disney films, at a rate of nearly one act per minute of programing, and friends were the most frequent targets for prosocial acts, followed by family and strangers.

Though these studies suggest that prosocial behavior is common in the media and is portrayed in complex ways, few studies have examined the effects of viewing such content. The General Learning Model (GLM; Buckley \& Anderson, 2006; Gentile, Groves, \& Gentile, 2014) theorizes that media can have both short and long term effects on subsequent behavior. In the short term, viewing prosocial content can influence cognition (by activating prosocial script in memory), arousal (by physiologically decreasing stress), and affect (by putting the person in a good mood). For example, if an adolescent views someone helping another person in a TV program, their thoughts regarding prosocial behavior are activated, they may feel more relaxed and less stressed, and they may feel happy; all characteristics that would then increase the likelihood that they would help another person if a relevant circumstance presented itself.

In the current study (see Figure 1) we apply the long-term or longitudinal processes described by the GLM as it relates to

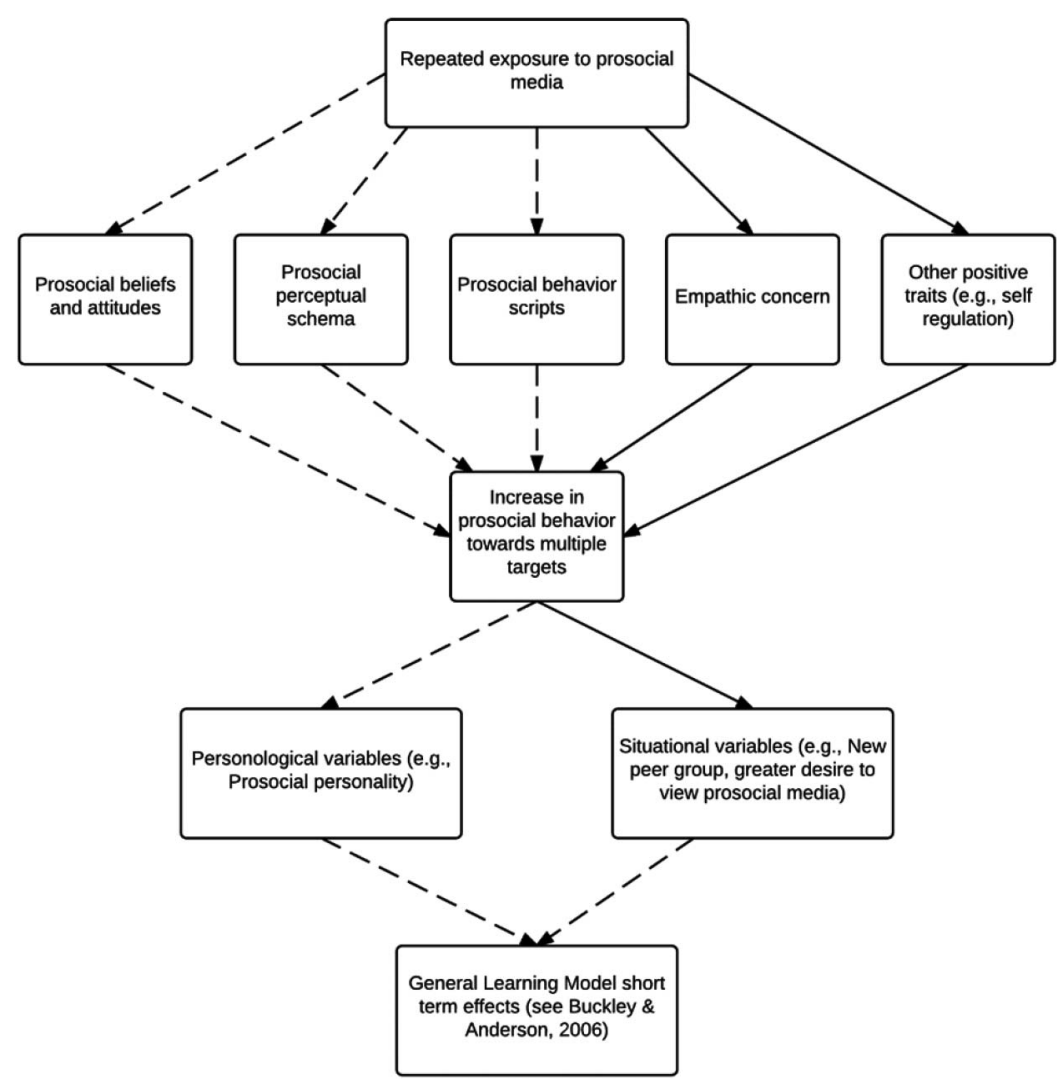

Figure 1. The General Learning Model: Long-term effects of viewing prosocial media. Note: Solid lines are tested in the current study. 
prosocial media (Buckley \& Anderson, 2006; Gentile et al., 2014). According to the theory, repeated viewing of prosocial behavior has the potential to shape prosocial-related knowledge structures, which may include cognitive scripts and norms involving prosocial behavior, empathic concern, and other positive traits, including self-regulation. These knowledge structures may then fundamentally change an individual's personality to be more prosocial, which is reflected in their behavior. In the current study, we test this part of the model by examining associations between early exposure to prosocial media and later empathic concern, selfregulation, and prosocial behavior toward multiple targets.

The GLM also describes how a prosocial personality may influence personological and situational variables over time. Personological variables include being more prosocial in traits, beliefs, attitudes, and behavior. Situational variables refer to changing situations, such as targeting a more prosocial peer group, changing social situations, or a greater desire to view prosocial media in the future. It is this last concept that we also examine in the current study. According to this portion of the GLM, having a prosocial personality or engaging in prosocial behavior can lead the individual to desire more prosocial media over time. Both personological and situational variables that develop over time (including a greater desire to view prosocial media) then predict ways a person responds to media in the short-term. Accordingly, in the current study we will examine paths between early prosocial behavior and prosocial disposition or personality (empathic concern and self-regulation), as well as later preference for prosocial media.

Lending support to the GLM, a meta-analysis found that viewing prosocial TV was associated with altruism, social interaction, and reduced aggression (Mares \& Woodard, 2005). Notably, most existing studies primarily focused on childhood, with very few examining effects on adolescents. In one exception, Prot et al. (2014) found that prosocial media (including TV) was concurrently related to prosocial behavior in adolescents and emerging adults in seven countries. It should also be noted that almost all research on prosocial media during adolescence has focused on prosocial video games and has found that adolescents who play prosocial video games tend to show higher levels of helping behavior, cooperation and sharing, empathic concern, and emotional awareness, again in line with the GLM (e.g., Greitemeyer \& Mügge, 2014).

That being said, very little is known about the longitudinal relations between prosocial media and subsequent behavior in adolescence, and more specifically, about the mechanisms behind the later paths hypothesized by the GLM. To our knowledge, there are currently only two longitudinal studies of prosocial media in the literature. Prot et al. (2014) examined long-term associations between playing prosocial video games and outcomes 2 years later in early adolescence ( $M$ age of 11-years-old). Playing prosocial video games was associated with higher levels of empathic concern 1 year later, which was then associated with prosocial behavior a year after that, providing support for the GLM. This study suggests a long-term effect of playing prosocial video games, however, was limited to early adolescence. Gentile et al. (2009) also examined longitudinal effects of playing prosocial video games, but in mid- ( $M$ age 13.6-years old) and later adolescence (16.6 years old). They found a cross-lagged relationship between playing prosocial video games and prosocial behavior 3-4 months later. This suggests a longitudinal, bidirectional effect, though the study was limited by a very short time lag of only a few months.

Taken together, these studies suggest that exposure to prosocial media may influence prosocial behavior longitudinally, and vice versa. While existing research sets a very important foundation for our understanding of the role of prosocial media, it is limited in a number of ways. Both longitudinal studies took place in Asian cultures (Japan and Singapore); accordingly, research is needed that examines effects in other cultures. Both studies also utilized a unidimensional concept of prosocial behavior, with no discussion of the target of behavior. Most notably, both focused exclusively on playing prosocial video games. Though this line of research indicates that playing prosocial video games can result in positive outcomes for adolescents, prosocial games are not frequently played by adolescents. On the other hand, content analyses show that prosocial behavior is relatively common in TV programs that are popular among adolescents (Smith et al., 2006). However, to our knowledge, there is no longitudinal research on the effects of viewing prosocial TV during adolescence. Finally, both longitudinal studies only focused on prosocial behavior as an outcome. However, cross-sectional and experimental studies suggest that prosocial media can also reduce aggressive behavior (e.g., Greitemeyer \& Mügge, 2014). Accordingly, it is possible that exposure to prosocial media may reduce aggressive behavior in the longterm, or that aggressive behavior may reduce selection of prosocial media over time. Thus, the current study involved a 3-year longitudinal study designed to fill these important research gaps.

\section{Empathic Concern and Self-Regulation as Longitudinal Mediators}

Another important gap in the current literature is an understanding of the mechanisms through which media might influence adolescents' behaviors and vice versa. Previous research has highlighted the consistent link between empathic concern and prosocial behavior (Eisenberg et al., 2006), defining empathic concern (also referred to as sympathy) as an emotional response of sorrow or concern for others that often stems from one's initial feelings of empathy (Eisenberg, 2000). In this way, empathic concern fosters prosocial behavior as the adolescent feels concerned for others and motivated to help (Hoffman, 2000). However, when an individual's empathy response is too strong or cannot be regulated, they may become overwhelmed with distress themselves and be unable to attend to the needs of others, an emotion called personal distress (Eisenberg et al., 2006). Thus, feelings of empathy may be manifested as either empathic concern or personal distress, in part because of one's ability to self-regulate. Thus, self-regulation is another potential factor that influences prosocial behavior and media use by permitting people to interpret, monitor, direct, and control their emotions or behaviors to reach a desired goal (Moilanen, Shaw, \& Fitzpatrick, 2010). In situations where an individual may be prone to overwhelming personal distress, if they are able to regulate their feelings and control their behavior, they are still able to help, highlighting self-regulation as an important predictor of prosocial behavior (Carlo, Crockett, Wolff, \& Beal, 2012; Eisenberg et al., 1994). Media use has also been linked to both empathic concern and self-regulation (Fraser, Padilla-Walker, Coyne, \& Nelson, 2012; Padilla-Walker \& Coyne, 2011), and prosocial media content has been associated with prosocial behav- 
ior via empathic concern (Greitemeyer, 2009; Prot et al., 2014). Thus, we examined these two dispositional factors (empathic concern and self-regulation) as mediators between prosocial media content and prosocial and aggressive behavior, and explored the possible direction of effects in this regard.

\section{Current Study}

The major aim of the current study was to examine longitudinal cross-lagged associations between prosocial TV content and adolescent outcomes, including prosocial behavior (toward three targets) and aggressive behavior. First, we explored whether viewing prosocial content at the initial time point would be positively associated with prosocial behavior toward strangers, friends, and family, and negatively associated with aggressive behavior 2 years later. This expands on the current literature by examining a longer gap between media exposure and behavior ( 2 years) and by assessing prosocial behavior as a multidimensional construct. It is also the first study, to our knowledge, to examine longitudinal effects of viewing prosocial content on aggressive behavior. We also explored whether prosocial behavior and aggression at the initial time point would be associated with media content 2 years later, as suggested by the GLM. Second, longitudinal research on prosocial TV has not yet examined mediating factors; accordingly, we expected that empathic concern and self-regulation would mediate these associations in the current study. Because dispositional traits are more strongly associated with prosocial behavior toward strangers than friends or family (Padilla-Walker \& Christensen, 2011), we thought it possible that indirect paths would be stronger for prosocial behavior toward strangers than other targets.

\section{Method}

\section{Participants and Procedure}

The participants for this study were selected from a larger project called the Flourishing Families Project (FFP), and data were used from thee time points (Times $3-5$ ), each $\sim 1$ year apart. The current study used a subsample $(n=441)$ of adolescents from the larger study $(N=500)$ who reported having at least one favorite TV show at Time 3 ( $M$ age of child at Time $3=13.31$, $S D=1.06 ; 52 \%$ female; $M$ age of child at Time $5=15.27, S D=$ 1.06). We used Times 3, 4, and 5 because media content data were not available until the third wave of the longitudinal project. Regarding ethnicity, $66 \%$ of families were European American, $13 \%$ were Black, and $20 \%$ were multiethnic. Thirty-four percent of adolescents came from single-parent families, and average combined monthly income (mother-reported) was $\sim \$ 5,500(\sim \$ 66,000$ yearly), but $21 \%$ of the sample reported making less than $\$ 3,000$ monthly ( $\sim \$ 36,000$ yearly).

Participant families for the FFP were selected from a large Northwestern city in the United States and were randomly selected from targeted census tracts that mirrored local school districts using a purchased national telephone survey database. Of the eligible families contacted, those agreeing to participate resulted in a $61 \%$ response rate. Of the families who participated at Wave 1, $91 \%$ had complete data at Wave 5 (see Padilla-Walker, Harper, \& Bean, 2011 for additional information on procedure). At each wave of data collection, researchers visited the family's home and administered questionnaires. Missing data (which were very minimal) were handled using the Full Information Maximum Likelihood feature of AMOS.

\section{Measures}

Prosocial and aggressive media. TV content and time of exposure were assessed at Time 3 and Time 5 by asking adolescents to name their three favorite TV shows, and how frequently they viewed each show on a scale ranging from 1 (once a month) to 5 (more than once a day). All the programs identified by participants were then distributed to 752 independent raters (37\% male, $M$ age $=23.67, S D=8.69)$ who were given complete definitions of prosocial (i.e., behavior intended to help others or benefit society as a whole) and aggressive (i.e., behavior intended to harm another person through physical means) behavior and examples (e.g., prosocial: helping, sharing, cooperating, supporting others; aggressive: shooting, stabbing, punching, biting others), and then were asked to rate how much prosocial and aggressive behavior were in each program with which they were familiar (viewed regularly). Raters were recruited from multiple high schools and universities across the United States and completed the ratings online. Ratings were based on a 1 (not prosocial or aggressive) to 5 (extremely prosocial or aggressive) Likert scale. The raters evaluated a total of 352 different programs. The mean ratings of all raters for a particular show (at least two raters per show) were determined. Intercoder reliability was assessed using interclass correlations (ICC) that are specifically appropriate when using continuous data (e.g., Shrout \& Fleiss, 1979). Expert ratings are commonly used in media violence research (e.g., Huesmann et al., 2003; Krahé, Busching, \& Möller, 2012) and show high reliability, convergent validity, predictive validity, and discriminant validity across multiple cultures and ages (Busching et al., 2013). ICCs showed moderate to strong reliability in the current study (Physical aggression ICC $=.80$; Prosocial behavior ICC $=$ .66). As a comparison, though they did not use this technique with prosocial behavior, Busching et al. (2013) found ICC of expert ratings of media violence that ranged from $.35-.80$ in the United States, Germany, and Singapore. Averages across the three shows were used for both prosocial (correlations ranged from $r=.15$ $.26, p<.05$ ) and aggressive content (correlations ranged from $r=$ $.20-.42, p<.01)$, with higher scores representative of more prosocial and aggressive content overall. Frequency of viewing favorite shows (time) was also averaged across the three shows. Finally, an interaction was calculated between content and the time (Anderson et al., 2010), averaged across the three shows. TV programs rated as highly prosocial included Arthur, Monk, and The Ghost Whisperer, while programs rated as highly aggressive included Ultimate Fighter, Breaking Bad, and Prison Break.

Empathic concern. Adolescents responded to seven items at Time 3 and Time 4 assessing their own empathic concern $(\alpha=$ .80-.83; Davis, 1983; e.g., "When I see someone being taken advantage of, I feel kind of protective towards them") based on a 5-point scale ranging from 1 (strongly disagree) to 5 (strongly agree).

Self-regulation. Adolescents reported on their own long-term self-regulation at Time 3 and Time 4 using four items from Novak and Clayton's (2001) self-regulation measure ( $\alpha=.73-.76$; e.g., "I develop a plan for all my important goals," "I think about the 
future consequences of my actions"). Responses ranged from 1 (never true) to 5 (always true).

Prosocial behavior. Adolescents reported on their own prosocial behavior toward strangers, friends, and family at Time 3 and 5 using a modified version of the Kindness and Generosity subscale of the Values in Action Inventory of Strengths (Peterson \& Seligman, 2004). The original measure was designed to assess behaviors toward strangers, and the current study used nine slightly adapted items to assess prosocial behavior toward strangers ( $\alpha=.91,92$; e.g., "I help people I don't know, even if it's not easy for me"). Similar items were adapted to assess prosocial behavior toward friends ( 9 items, $\alpha=.89, .90$, "I go out of my way to cheer up my friends") and family (9 items, $\alpha=.91,92$; e.g., "I really enjoy doing small favors for my family") on a 5-point Likert scale ranging from 1 (not like me at all) to 5 (very much like me).

Aggression. Adolescents reported on their own physically aggressive behavior at Time 3 and 5 using five items $(\alpha=.87, .88$; e.g., "I lose my temper and 'let people have it' when I'm angry; Weinberger \& Schwartz, 1990) on a 5-point Likert scale ranging from 1 (does not describe me/my child) to 5 (describes me/my child very well). This measure has been validated and displayed adequate internal reliability in multiple studies with this age group (e.g., Monahan, Steinberg, Cauffman, \& Mulvey, 2009; Williams \& Steinberg, 2011).

Controls. Controls at Time 3 included gender (boys had the higher coded value), family structure (single parents had the higher coded value), family income, and total time spent watching TV. Adolescents responded to the question, "How much time do you spend on a typical day watching TV programs?" on a scale ranging from 1 (none) to 9 (more than 8 hours).

\section{Analytical Strategy}

It should be noted that when dealing with statistical interaction terms (in this case, the interaction or product term between media content and media time), to get correct model specification it is essential to also consider the main effects of each variable (Aiken, West, Luhmann, Baraldi, \& Coxe, 2012). This is done, in part, so that one can determine if there is a signification multiplicative effect over and above what is already accounted for by content and time, considered separately. In other words, if one considers an interaction without considering the main effects as well, it is unclear whether one or both of the main effects is accounting for the significant association between the interaction and outcomes. Further, if a significant interaction effect is found, follow up simple slope analyses should be conducted to determine the interpretation of the interaction (Aiken et al., 2012; Tabachnick \& Fidell, 2012). This is a normative approach in the regression literature and when considering interactions, and has been demonstrated by numerous studies examining adolescent development (e.g., Chen \& Vazsonyi, 2011; Gibbons et al., 2012; Mann, Kretsch, Tackett, Harden, \& Tucker-Drob, 2015), but has not always been considered when examining the effects of media. A more typical approach when examining media effects is to create a multiplicative term between media content and media time and to treat this interaction term as a main effect of media dosage, without also including the two main effects of media time and media content, and without conducting simple slope analyses to follow up the interpretation of any significant interaction effect (e.g., Gentile et al., 2009; Prot et al., 2014). Although this approach may make conceptual sense, statistically it tells us little about the main effects of media content compared with media time, and how these two variables might interact with one another. Thus, in the current study we considered media time, media content, and the interaction between the two in the hopes of understanding more fully how media might impact adolescent behavior (and vice versa) over time.

With this in mind, the current study examined two models. First we examined direct cross-lagged paths between prosocial and aggressive content and time (frequency of viewing favorite shows), and the interaction between content and time; and prosocial (toward strangers, friends, and family) and aggressive behavior. All variables were examined both at Time 3 and Time 5 . Second, we examined a direct and indirect model (where we added empathic concern and self-regulation as potential mediators at Time 4; controlled for at Time 3). Thus, in the first model we examined direct paths only, and in the second model we examined both direct and indirect paths (see Figure 2 for the second or final model).

\section{Results}

\section{Descriptive Statistics and Correlations}

Table 1 contains correlations and descriptive statistics between all continuous study variables. Family income was not associated with any of the study variables, so it was dropped from the table for parsimony. Overall time watching TV and time watching favorite TV shows at Time 3 were both negatively associated with prosocial behavior and positively associated with aggression at Time 5. Prosocial behavior (toward all three targets) at Time 3 was associated with both empathic concern and self-regulation at Time 3 and Time 4. In turn, empathic concern and self-regulation at Time 4 were positively associated with all three targets of prosocial behavior and negatively with aggression at Time 5. Empathic concern at Time 4 was positively associated with prosocial and negatively associated with aggressive content at Time 5, and self-regulation at Time 4 was negatively associated with aggressive content at Time 5 .

The most popular TV shows reported by teens were The Family Guy, Glee, and The Office. Other favorites with more than $2 \%$ of the sample mentioning them included South Park, Modern Family, The Simpsons, Sponge Bob Square Pants, Sports Center, and American Idol. $T$ tests revealed that girls (Time 3: $M=3.31, S D=$ .53 ; Time $5: M=3.36, S D=.50)$ reported watching $\mathrm{TV}$ with higher prosocial content than did boys (Time 3: $M=3.20, S D=$ .48 ; Time 5: $M=3.19, S D=.41)$ at Time $3, t(414)=2.11, p<$ .05 and Time $5, t(388)=3.66, p<.001$; and boys (Time $3: M=$ $3.04, S D=.87$; Time $5: M=3.15, S D=.86)$ reported watching TV with higher aggressive content than did girls (Time 3: $M=$ 2.41, $S D=.97$; Time 5: $M=2.92, S D=.92$ ) at Time 3, $t(420)=-6.95, p<.001$ and Time $5, t(392)=-2.57, p<.05$.

\section{Cross-Lagged Paths Between Prosocial TV Content and Adolescents' Prosocial Behavior and Aggression}

Child gender, family structure, and total TV time were used as control variables in all analyses. Family income was explored as a 


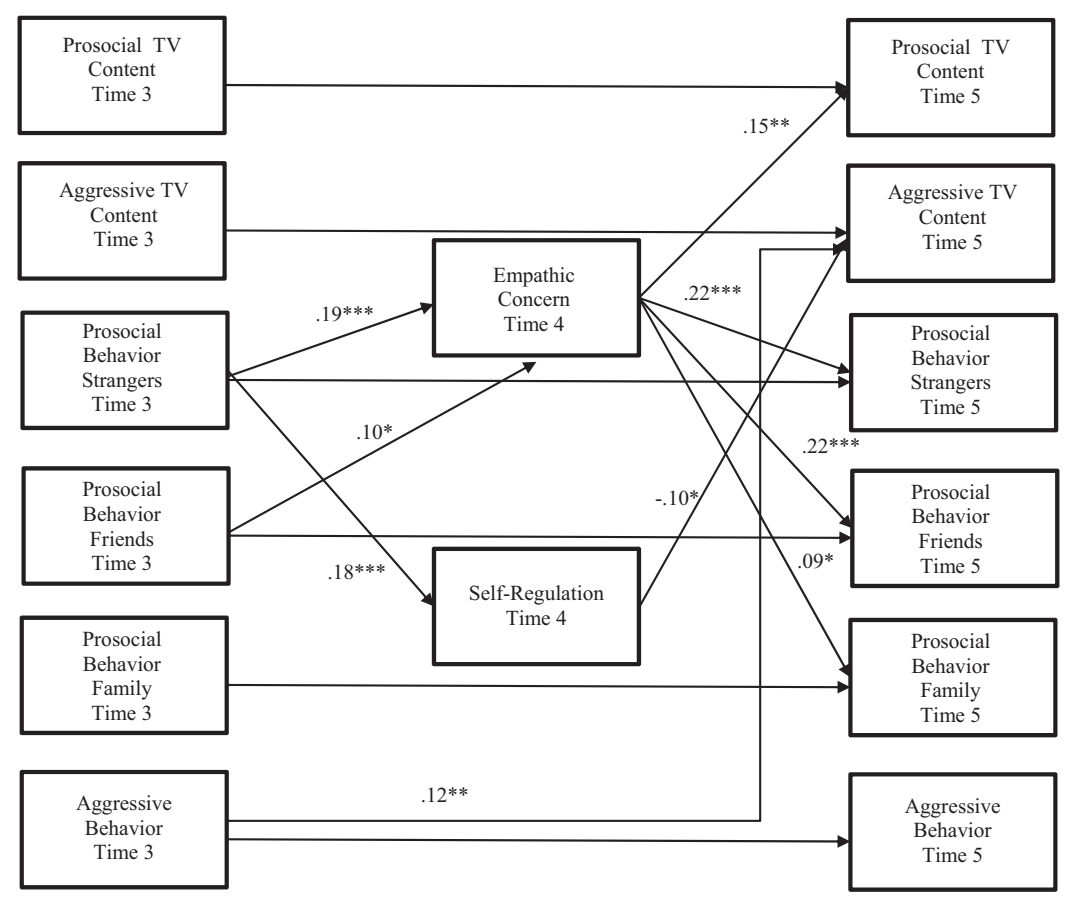

Figure 2. Longitudinal cross-lagged relations between prosocial TV and adolescents' prosocial and aggressive behaviors. Note: $\chi^{2}(55)=85.96, p<.01, \mathrm{CFI}=.99$, RMSEA $=.04$. Exogenous covariances, endogenous error correlations, and stability coefficients are not shown for parsimony. Only significant standardized weights are shown, with the exception of stability paths, which are reported in text. Gender, total screen time, family structure, empathic concern, and self-regulation are controls at Time 3 . The main effect of time watching favorite shows and interactions between prosocial content and time were not significant, so were not included in the model. ${ }^{*} p<.05,{ }^{* *} p<.01,{ }^{* * *} p<.001$.

control variable, but was not associated with any of the variables of interest, so was dropped from analyses. Because of the number of variables examined, we did not have adequate power to use latent variables, so manifest variables were used for all constructs. In both models, exogenous variables were correlated with one another at Time 3 and residual error terms for self-reported outcome variables were correlated at Time 5. For the second model, residual error terms for empathic concern and self-regulation were correlated at Time 4. These are not shown in Figure 2 for parsimony. It should be noted that the main effect of time and the interaction between prosocial content and time and between aggressive content and time were not significant in any of the models, and they did not alter any of the findings, so they were dropped for parsimony.

The direct model had good model fit $\left(\chi^{2}(32)=63.53, p<.001\right.$, $\mathrm{CFI}=.98$, RMSEA $=.05)$. Prosocial content at Time 3 was directly and negatively associated with aggression at Time 5 $(\beta=-.09, p<.05)$ and aggressive content at Time 3 was directly and negatively associated with prosocial behavior toward strangers at Time $5(\beta=-.09, p<.05)$. In addition, aggression at Time 3 was directly and positively associated with aggressive content at Time $5(\beta=.12, p<.01)$. There were also a number of trends or marginally nonsignificant paths $(p<.10)$, including prosocial content at Time 3 to prosocial behavior toward family at Time 5 $(\beta=.07)$; and aggressive content at Time 3 to prosocial behavior toward family $(\beta=-.07)$ and aggressive behavior $(\beta=.07)$ at
Time 5. However, these paths were only trends and should, therefore, be interpreted with caution.

Next, the mediators and indirect effects were added to the model $\left(\chi^{2}(50)=84.27, p<.01, \mathrm{CFI}=.99\right.$ RMSEA $=.04$; see Figure 2). Direct paths were no longer significant with the mediators in the model with one exception. Aggression at Time 3 was still directly associated with aggressive content at Time $5(\beta=.12$, $p<.05)$. Prosocial content at Time 3 was also marginally negatively associated with aggression at Time $5(\beta=-.08, p=.06)$. Prosocial and aggressive content at Time 3 were not associated with the mediators at Time 4 . However, prosocial behavior toward strangers at Time 3 was positively associated with empathic concern $(\beta=.19, p<.001)$ and self-regulation $(\beta=.18, p<.001)$ at Time 4 , and prosocial behavior toward friends at Time 3 was positively associated with empathic concern at Time $4(\beta=.10$, $p<.05)$. In turn, empathic concern at Time 4 was positively associated with prosocial content at Time $5(\beta=.15, p<.01)$ and self-regulation was negatively associated with aggressive content at Time $5(\beta=-.10, p<.05)$. Self-regulation at Time 4 was not associated with any of the behavioral outcomes at Time 5, but empathic concern at Time 4 was positively associated with prosocial behavior toward strangers $(\beta=.22, p<.001)$, friends $(\beta=$ $.22, p<.001)$, and family $(\beta=.09, p<.05)$.

To examine the significance of indirect effects, we conducted bootstrapping analyses based on 2,000 bootstrap resamples and a $95 \%$ confidence interval (CI). This analysis revealed a significant 


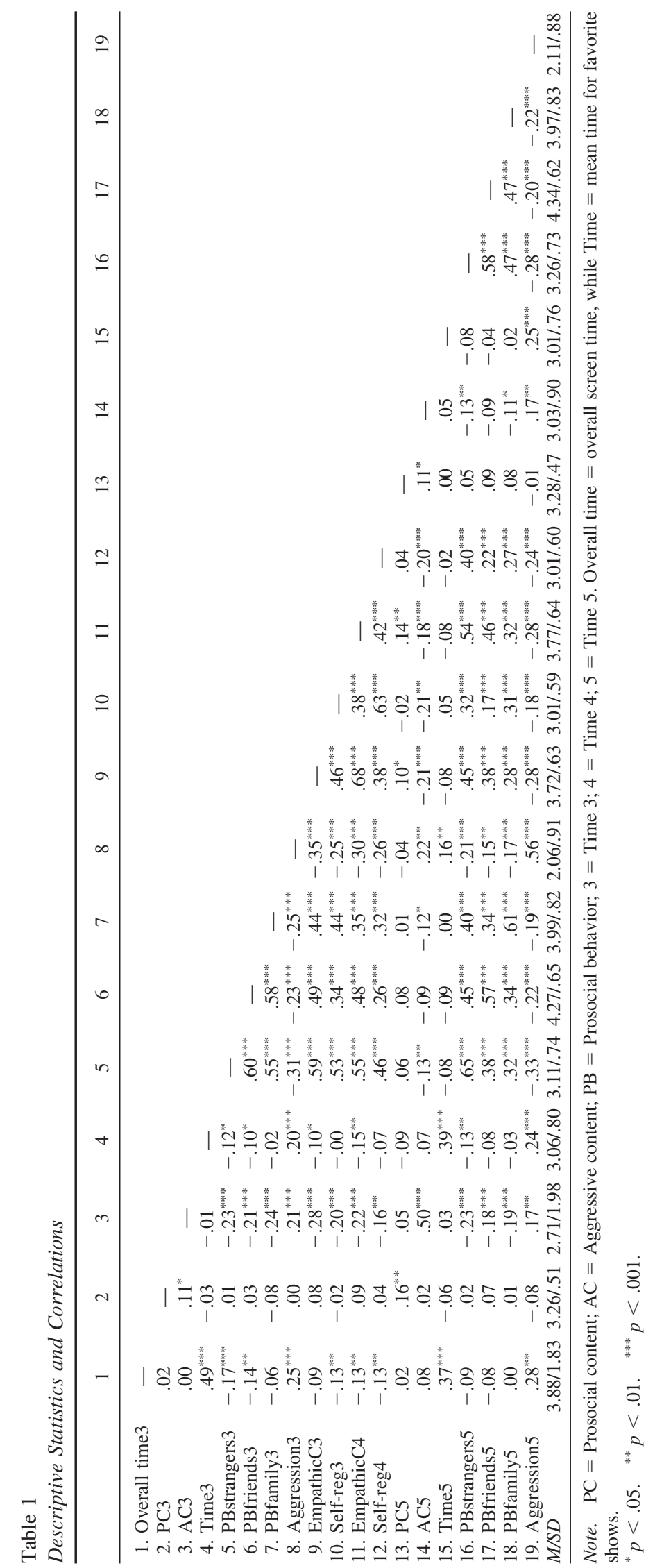


indirect effect via empathic concern between prosocial behavior toward strangers at Time 3 and prosocial content at Time 5 (standardized indirect effect $=.06, \mathrm{CI}=.02-.11, p<.01)$; and between prosocial behavior toward strangers at Time 3 and prosocial behavior toward friends (standardized indirect effect $=.08$, $\mathrm{CI}=.03-.13, p<.01$ ) and strangers (standardized indirect effect $=.10, \mathrm{CI}=.05-.16, p<.001)$ at Time 5. There were also indirect effects via empathic concern between prosocial behavior toward friends at Time 3 and prosocial content at Time 5 (standardized indirect effect $=.02, \mathrm{CI}=.00-.06, p<.05$ ); between prosocial behavior toward friends at Time 3 and prosocial behavior toward family (standardized indirect effect $=.01, \mathrm{CI}=.00-.04$, $p<.05$ ), friends (standardized indirect effect $=.03, \mathrm{CI}=.01-.06$, $p<.001$ ), and strangers (standardized indirect effect $=.04, \mathrm{CI}=$ $.01-.07, p<.01)$ at Time 5. Analyses also revealed significant indirect effects via self-regulation between prosocial behavior toward strangers at Time 3 and aggressive content at Time 5 (standardized indirect effect $=-.03, \mathrm{CI}=-.12$ to $-.03, p<.01)$. It should also be noted that there was a significant total effect (direct plus indirect via self-regulation) of prosocial content at Time 3 on aggression at Time 5 (standardized total effect $=-.08$, $\mathrm{CI}=-.16-.00, p=.05)$.

In terms of controls (all measured at Time 3), gender (boys had higher coded value) was negatively associated with empathic concern at Time $4(\beta=-.13, p<.001)$ and prosocial behavior toward friends at Time $5(\beta=-.11, p<.001)$; family structure (single parent home had higher coded value) was negatively associated with empathic concern at Time $4(\beta=-.11, p<.01)$; and overall TV time was positively associated with aggression at Time $5(\beta=.14, p<.01)$. It should also be noted that all stability paths were statistically significant, including prosocial content $(\beta=.14$, $p<.01)$, antisocial content $(\beta=.47, p<.001)$, empathic concern $(\beta=.48, p<.001)$, self-regulation $(\beta=.52, p<.001)$, prosocial behavior toward strangers $(\beta=.51, p<.001)$, friends $(\beta=.43$, $p<.001)$, and family $(\beta=.56, p<.001)$; and aggression $(\beta=$ $.48, p<.001)$.

\section{Discussion}

The current study examined longitudinal cross-lagged relations between viewing prosocial content on TV and prosocial and aggressive behavior. When direct paths between media and behavioral outcomes were examined, prosocial TV content (but not time watching these shows or the interaction between content and time) directly predicted lower levels of aggression, and marginally higher levels of prosocial behavior toward family 2 years later. To our knowledge this is the first study to show a long-term, albeit small, relation between viewing prosocial content on TV and later aggressive behavior. Although it should be interpreted with caution, this finding can be well explained by the GLM (Buckley \& Anderson, 2006) and suggests that prosocial content on TV may have a small socializing effect on reducing later aggression. This result confirms a number of experimental studies (e.g., Greitemeyer, Agthe, Turner, \& Gschwendtner, 2012; Greitemeyer, \& Osswald, 2009; Saleem, Anderson, \& Gentile, 2012) that show that playing prosocial video games can decrease aggressive behavior in adolescence, and extends it to the long term and another medium.
Additionally, early exposure to aggressive TV content predicted lower levels of prosocial behavior to strangers and to family members (at a trend level) and marginally higher levels of aggression 2 years later. Aggressive behavior at Time 3 was also directly associated with aggressive content at Time 5. However, these direct paths were rather small in nature and were not explained by significant indirect effects once mediators were added to the model. Because the link between aggressive content and behavior is relatively well established in the literature (e.g., Anderson et al., 2010), we speculated as to why this path was weak in the current study. One possibility is that the effects of aggressive media content, when also taking prosocial media content into account in a multivariate model, may not strongly predict prosocial and aggressive outcomes over a 2 year time period during adolescence. Future research should continue to consider both aggressive and prosocial content in the same model to gather a more holistic view of how multiple types of content influence teens. Another possibility is that aggression is not a strong enough indicator of problem behavior during adolescence, at least not as it was measured in the current study with a relatively well-adjusted sample, and that perhaps aggressive media content is associated with what might be considered more severe behavioral manifestations of aggression, such as delinquent behavior (e.g., DeLisi et al., 2013). Indeed, post hoc analyses revealed that there were consistent direct cross-lag paths (in both direct and indirect models) between aggressive media content and delinquent behavior 2 years later, ${ }^{1}$ suggesting that perhaps the stakes are higher during adolescence, and the impact of media content is more salient for delinquency than aggression during this developmental period. Future research should consider this possibility.

\section{Indirect Effects via Empathic Concern and Self-Regulation}

Though there were no indirect effects of media content on later behavior, analyses did provide support for the later paths described in the GLM, where early prosocial behavior and related traits predicted later exposure to prosocial TV during adolescence. More specifically, higher levels of prosocial behavior toward strangers and friends predicted more empathic concern 1 year later, which in turn predicted viewing higher levels of prosocial content on TV a year after that. As adolescents help strangers in particular, they are likely to develop empathic concern, and these feelings of concern may then motivate them to seek out increasing portrayals of prosocial behavior in the media. Similarly, prosocial behavior toward strangers predicted higher levels of self-regulation 1 year later, which then predicted lower levels of aggressive content a

\footnotetext{
${ }^{1}$ In post hoc analyses, identical models were run to those reported in the results, but adolescent delinquency was substituted for adolescent aggression. All other aspects of this model were comparable to the model with aggression, including fit statistics and strength of $\beta$ weights. In the indirect post hoc model, however, there was a positive link between aggressive content at Time 3 and delinquency at Time $5(\beta=.13, p<.01)$, as well as between delinquency at Time 3 and aggressive content at Time 5 ( $\beta=$ $.11, p<.05)$. Prosocial content at Time $3(\beta=-.11, p<.01)$ and self-regulation at Time 4 were also negatively associated with delinquency at Time $5(\beta=-.16, p<.001)$. Delinquency and aggression were only modestly correlated $(r=.38-.42)$. Delinquency items included behaviors such as destroying others' property, using alcohol or drugs, lying, cheating, and skipping school.
} 
year after that. It is possible that adolescents who are more prosocial toward strangers (i.e., generally seen as a high-cost behavior; Padilla-Walker \& Fraser, 2014) view depictions of media violence as less desirable, offensive, or unacceptable, even though aggressive content is both popular and widespread in adolescent media. Accordingly, the development of self-regulation may help adolescents be more choosy in their media content and thus, less likely to view aggressive content on TV. Our results do not specifically speak to why prosocial, empathetic adolescents who are good at self-regulating seek out prosocial behavior on TV and less aggression in the long-term, but it is likely a function of prosocial personality and identity, which have been shown to be associated with a number of positive behavior patterns (Eisenberg et al., 2006). Indeed, research suggests that engaging in prosocial behavior is associated with higher levels of personality traits indicative of prosocial personality (such as empathic concern and selfregulation), which traits are then reciprocally associated with higher levels of prosocial behavior (Carlo, Padilla-Walker, \& Nielson, 2015; Padilla-Walker \& Fraser, 2014). The current study extends this research to suggest that prosocial behavior and personality might also impact one's choice of media. While the indirect effects in the current study were generally small, we can speculate that viewing prosocial programs may confirm positive behaviors and traits in adolescents, which may help cement their existing prosocial and moral personality and identity, as explained in the GLM (Buckley \& Anderson, 2006; Hart et al., 1998).

\section{Comparisons With Existing Prosocial Media Studies}

Taken together, these findings are somewhat inconsistent with the two longitudinal studies on prosocial media content as it relates to prosocial behavior during adolescence, which either found that playing prosocial video games predicted later prosocial behavior (and not the other way around; Prot et al., 2014) or that there were clear bidirectional effects of playing prosocial video games on prosocial behavior, and of prosocial behavior on later prosocial video game play (Gentile et al., 2009). Findings were also inconsistent in that past research has found empathic concern to mediate the relation between media content and prosocial behavior (Prot et al., 2014), while the current study only found mediation between behavior at the initial time point and media content 2 years later. There are a number of explanations for the conflicting findings. First, our study examined prosocial content on TV. Unlike prosocial video games, where such behavior is infrequent or often paired with violence (Coyne, \& Smith, 2014), prosocial behavior on TV is common and on average is portrayed multiple times in most programs viewed by adolescents (Smith et al., 2006). In video games, violence, and not prosocial behavior, is the norm. Accordingly, prosocial content in video games may act as a greater socializing agent as compared with TV in the long term development of prosocial behavior.

Another explanation may be that prosocial content on TV simply does not have a long-term effect on the development of empathic concern or prosocial behavior during mid-adolescence. According to the GLM, early exposure to prosocial media may directly shape an individual's personality. However, much of this shaping may take place during childhood when most of the development regarding prosocial norms are taking place (e.g., Carlo, Crockett, Randall, \& Roesch, 2007). Prot et al. (2014) found a long-term effect on both empathy and prosocial behavior, but their participants were substantially younger than in the current sample. By mid-adolescence empathic concern and prosocial behavior are considered to be fairly stable (e.g., Carlo et al., 2007) in large part because of genetic factors (Gregory, Light-Hausermann, Rijsdijk, \& Eley, 2009). Indeed, we find that other positive socializing influences on prosocial behavior, such as positive parenting, are much more salient during childhood and that direct relations between parenting and outcomes are more difficult to find, especially during mid to late adolescence (see Padilla-Walker, 2014). Thus, it may not be surprising that there are smaller socialization effects of media during this developmental period as well. Gentile et al. (2009) did find a longitudinal effect of playing prosocial video games in older adolescence, but the time lag was only 3-4 months between measurement. Given how small the long-term effect of prosocial media has been in existing studies, it is possible that prosocial media has a short-term longitudinal effect during adolescence, but does not significantly increase empathic concern or prosocial behavior years later, explaining both the lack of indirect and direct long-term effects in the current study.

Another related issue is that many past studies examining media effects considered only the interaction between media content and media time without also considering main effects (e.g., Gentile et al., 2009; Prot et al., 2014). It could be that when the main effects are taken into account, the same patterns or the same strength of patterns are not found. Indeed, in the current study we found no effect of media time or of the interaction between media content and time, suggesting that media content was the most salient aspect of media effects and media selection. Certainly future research considering both main effects of content and time, as well as the interaction between the two (with simple slope follow-ups for interpretation) needs to be conducted to further understand the complexity of media effects.

Additionally, this study examined prosocial behavior as a multidimensional construct, while other media studies have characterized it as a unidimensional one. The results suggest that prosocial behavior targeted toward strangers, and to a lesser extent friends, may be particularly important in our understanding of the relations between prosocial behavior on TV and in real life. This is an important finding because while prosocial behavior aimed at strangers is relatively infrequent compared with other targets, prosocial behavior toward strangers is the most directly protective for adolescents (i.e., associated with longitudinal decreases in problem behaviors; Padilla-Walker et al., in press). Prosocial behavior toward strangers is often considered to be a higher-cost behavior, as it frequently consists of time invested in volunteer work with those who are, at least initially, unknown to the adolescent (Padilla-Walker \& Fraser, 2014). Research suggests that high cost prosocial behavior is particularly important for the development of moral identity and personality (Hart et al., 1998), which was supported by current findings suggesting a link between prosocial behavior toward strangers and indicators of moral personality (i.e., empathic concern and self-regulation). These findings extend existing research by suggesting that prosocial behavior toward strangers is also indirectly associated with choice of media content, which may continue to shape moral identity. Given the importance of target, future research could examine how viewing prosocial behavior in the media aimed at a specific target may influence prosocial behavior directed toward specific targets. 
Finally, another possibility for the differences in the current study as compared with existing work involves methodology. Both Prot et al. (2014) and Gentile et al. (2009) utilized self-reports of prosocial content in video games, meaning adolescents rated their own video games in terms of prosocial content. This means that the same video game can potentially receive very different ratings of prosocial content because it is being rated by different raters. An individual's perception of the levels of prosocial content in any given program is likely dependent on his or her own experiences with prosocial behavior, so it is possible that prosocial adolescents "see" and then report more prosocial content in their own media as a function of their prosocial behavior or personality. In the current study we had a sample of over 700 individuals independently rate each TV program on prosocial content, which Huesmann et al. (2003) argue may represent a more objective approach to studying media content. Though self-reports of media content have been utilized frequently in the media violence literature and show a high positive correlation with expert ratings (Busching et al., 2013; Gentile et al., 2004), we suspect that prosocial content is far more difficult to rate. For example, prosocial content is very often paired with physical violence in video games and adolescents may rate a video game like Call of Duty as highly prosocial as players are "helping" a community by graphically killing others. Though playing violent video games with prosocial intent is not as harmful as playing violent games with selfish motivations (Gitter et al., 2013), prosocial aggression is not a construct that is consistently measured by researchers who study prosocial behavior (though there are exceptions), nor is it captured in most existing measures of prosocial behavior. Indeed, in the current study, we found that prosocial and aggressive content on TV were positively associated. Though the correlation was small, this suggests that "purely" prosocial programs, even on TV, may be rare. We suspect that the best methodology would utilize an objective content analysis of prosocial content in each program. While we recognize that this method is difficult and time consuming, we hope that future studies examine how self and expert ratings and content analyses of prosocial behavior in the media are associated, and what is the optimum way to capture these behaviors in an individual's media diet.

\section{Limitations and Conclusions}

Though the current study had many strengths, including a longitudinal design and relatively large sample, there were also a number of notable limitations. First, the participants were only moderately ethnically and socioeconomically diverse, which may impact generalizability of results. Additionally, we only used participants' three favorite TV programs as a representation of their exposure to prosocial TV content. Though this is a commonly used method in media research, adolescents likely view more than three TV programs. In the future, researchers may wish to have adolescents keep a daily diary of all TV content viewed to examine the total impact of TV on prosocial behavior. Finally, we only examined the long-term effects of viewing prosocial content on TV during mid-adolescence. Though we did not find many socializing effects of viewing prosocial content, it may be that prosocial media is a greater socializing agent at younger ages. We hope that longitudinal studies examine the long-term effect of viewing prosocial content throughout childhood, adolescence, and beyond.
Despite these limitations, this is the first longitudinal crosslagged study to examine how viewing prosocial content on TV is associated with prosocial behavior and aggression across adolescence. The results show evidence for various parts of the GLM, with the most consistent support for the latter part of the model where behavior and traits predict later viewing of prosocial and aggressive TV content. These findings speak to the power of examining the viewer and taking into account his or her preexisting behaviors and tendencies as motivations for seeking out positive portrayals in the media. Research should continue to move toward a more multidimensional characterization of prosocial behavior and should also examine both prosocial content and time (as main effects and an interaction), as in the current study we found that prosocial content was the most consistently associated with behavior. We also encourage parents to help their adolescents engage in prosocial behavior, especially toward strangers, as these behaviors may be particularly protective over time.

\section{References}

Aiken, L. S., West, S. G., Luhmann, M., Baraldi, A., \& Coxe, S. J. (2012) Estimating and graphing interactions. APA handbook of research methods in psychology: Vol. 3. Data. analysis and research publication (pp. 101-129). Washington, DC: American Psychological Association Press.

Amato, P. R. (1990). Personality and social network involvement as predictors of helping behavior in everyday life. Social Psychology Quarterly, 53, 31-43. http://dx.doi.org/10.2307/2786867

Anderson, C. A., Shibuya, A., Ihori, N., Swing, E. L., Bushman, B. J., Sakamoto, A., . . . Saleem, M. (2010). Violent video game effects on aggression, empathy, and prosocial behavior in eastern and western countries: A meta-analytic review. Psychological Bulletin, 136, 151173. http://dx.doi.org/10.1037/a0018251

Buckley, K. E., \& Anderson, C. A. (2006). A theoretical model of the effects and consequences of playing video games. In P. Vorderer \& J. Bryant (Eds.) Playing video games: Motives, responses, and consequences (pp. 363-378). Mahwah, NJ: Erlbaum.

Busching, R., Gentile, D. A., Krahé, B., Möller, I., Khoo, A., Walsh, D. A., \& Anderson, C. A. (2013). Testing the Reliability and Validity of Different Measures of Violent Video Game Use in the United States, Singapore, and Germany. Psychology of Popular Media Culture. Advance online publication.

Caprara, G. V., Barbaranelli, C., Pastorelli, C., Bandura, A., \& Zimbardo, P. G. (2000). Prosocial foundations of children's academic achievement. Psychological Science, 11, 302-306. http://dx.doi.org/10.1111/14679280.00260

Carlo, G., Crockett, L., Randall, B., \& Roesch, S. (2007). A latent growth curve analysis of prosocial behavior among rural adolescents. Journal of Research on Adolescence, 17, 301-324. http://dx.doi.org/10.1111/j 1532-7795.2007.00524.x

Carlo, G., Crockett, L. J., Wolff, J. M., \& Beal, S. J. (2012). The role of emotional reactivity, self-regulation, and puberty in adolescents' prosocial behaviors. Social Development, 21, 667-685. http://dx.doi.org/ 10.1111/j.1467-9507.2012.00660.x

Carlo, G., Mestre, M. V., McGinley, M. M., Tur-Porcar, A., Samper, P., \& Opal, D. (2014). The protective role of prosocial behaviors on antisocial behaviors: The mediating effects of deviant peer affiliation. Journal of Adolescence, 37, 359-366. http://dx.doi.org/10.1016/j.adolescence.2014 .02 .009

Carlo, G., Padilla-Walker, L. M., \& Nielson, M. G. (2015). Bidirectional longitudinal relations between sympathy and prosocial behavior during adolescence. Manuscript submitted for publication. 
Chen, P., \& Vazsonyi, A. T. (2011). Future orientation, impulsivity, and problem behaviors: A longitudinal moderation model. Developmental Psychology, 47, 1633-1645. http://dx.doi.org/10.1037/a0025327

Coyne, S. M., Callister, M., \& Robinson, T. (2010). Yes, another teen movie: Three decades of physical violence in films aimed at adolescents. Journal of Children and Media, 4, 387-401. http://dx.doi.org/10.1080/ 17482798.2010.510006

Coyne, S. M., \& Smith, N. J. (2014). Sweetness on the screen. In L. M. Padilla-Walker \& G. Carlo (Eds.), Prosocial development: A multidimensional approach (pp. 156-177). New York, NY: Oxford University Press. http://dx.doi.org/10.1093/acprof:oso/9780199964772.003.0008

Davis, M. H. (1983). The effects of dispositional empathy on emotional reactions and helping: A multidimensional approach. Journal of Personality, 51, 167-184. http://dx.doi.org/10.1111/j.1467-6494.1983 .tb00860.x

DeLisi, M., Vaughn, M. G., Gentile, D. A., Anderson, C. A., \& Shook, J. J. (2013). Violent video games, delinquency, and youth violence: New evidence. Youth Violence and Juvenile Justice, 11, 132-142. http://dx .doi.org/10.1177/1541204012460874

Eberly, M. B., \& Montemayor, R. (1999). Adolescent affection and helpfulness toward parents: A 2-year follow-up. The Journal of Early Adolescence, 19, 226-248. http://dx.doi.org/10.1177/0272431699019002005

Eisenberg, N. (1983). Children's differentiation among potential recipients of aid. Child Development, 54, 594-602. http://dx.doi.org/10.2307/ 1130046

Eisenberg, N. (2000). Emotion, regulation, and moral development. Annual Review of Psychology, 51, 665-697. http://dx.doi.org/10.1146/annurev .psych.51.1.665

Eisenberg, N., Fabes, R. A., Murphy, B., Karbon, M., Maszk, P., Smith, M., . . . Suh, K. (1994). The relations of emotionality and regulation to dispositional and situational empathy-related responding. Journal of Personality and Social Psychology, 66, 776-797. http://dx.doi.org/ 10.1037/0022-3514.66.4.776

Eisenberg, N., Fabes, R. A., \& Spinrad, T. L. (2006). Prosocial development. In N. Eisenberg (Ed.), Handbook of child psychology (pp. 646718). New York, NY: Wiley.

Ferguson, C. J., San Miguel, C., \& Hartley, R. D. (2009). A multivariate analysis of youth violence and aggression: The influence of family, peers, depression, and media violence. The Journal of Pediatrics, 155, 904-908.e3. http://dx.doi.org/10.1016/j.jpeds.2009.06.021

Fraser, A. M., Padilla-Walker, L. M., Coyne, S. M., \& Nelson, L. J. (2012). Associations between violent video gaming, empathic concern, and prosocial behavior toward strangers, friends, and family members. Journal of Youth and Adolescence, 41, 636-649. http://dx.doi.org/10.1007/ s10964-012-9742-2

Gentile, D. A., Anderson, C. A., Yukawa, S., Ihori, N., Saleem, M., Ming, L. K., .. Sakamoto, A. (2009). The effects of prosocial video games on prosocial behaviors: International evidence from correlational, longitudinal, and experimental studies. Personality and Social Psychology Bulletin, 35, 752-763. http://dx.doi.org/10.1177/0146167209333045

Gentile, D. A., Coyne, S., \& Walsh, D. A. (2011). Media violence, physical aggression, and relational aggression in school age children: A shortterm longitudinal study. Aggressive Behavior, 37, 193-206. http://dx.doi .org/10.1002/ab.20380

Gentile, D. A., Groves, C. L., \& Gentile, J. (2014). The general learning model: Unveiling the teaching potential of video games. In F. C. Blumberg (Ed., Learning by playing: Video gaming in education (pp. 121142). New York, NY: Oxford University Press. http://dx.doi.org/ 10.1093/acprof:osobl/9780199896646.003.0009

Gentile, D. A., Lynch, P. J., Linder, J. R., \& Walsh, D. A. (2004). The effects of violent video game habits on adolescent hostility, aggressive behaviors, and school performance. Journal of Adolescence, 27, 5-22. http://dx.doi.org/10.1016/j.adolescence.2003.10.002
Gibbons, F. X., Roberts, M. E., Gerrard, M., Li, Z., Beach, S. R., Simons, R. L., , . Philibert, R. A. (2012). The impact of stress on the life history strategies of African American adolescents: Cognitions, genetic moderation, and the role of discrimination. Developmental Psychology, 48, 722-739. http://dx.doi.org/10.1037/a0026599

Gitter, S. A., Ewell, P. J., Guadagno, R. E., Stillman, T. F., \& Baumeister, R. F. (2013). Virtually justifiable homicide: The effects of prosocial contexts on the link between violent video games, aggression, and prosocial and hostile cognition. Aggressive Behavior, 39, 346-354. http://dx.doi.org/10.1002/ab.21487

Gregory, A. M., Light-Häusermann, J. H., Rijsdijk, F., \& Eley, T. C. (2009). Behavioral genetic analyses of prosocial behavior in adolescents. Developmental Science, 12, 165-174. http://dx.doi.org/10.1111/j.14677687.2008.00739.x

Greitemeyer, T. (2009). Effects of songs with prosocial lyrics on prosocial behavior: Further evidence and a mediating mechanism. Personality and Social Psychology Bulletin, 35, 1500-1511. http://dx.doi.org/10.1177/ 0146167209341648

Greitemeyer, T., Agthe, M., Turner, R., \& Gschwendtner, C. (2012). Acting prosocially reduces retaliation: Effects of prosocial video games on aggressive behavior. European Journal of Social Psychology, 42, 235-242. http://dx.doi.org/10.1002/ejsp.1837

Greitemeyer, T., \& Mügge, D. O. (2014). Video games do affect social outcomes: A meta-analytic review of the effects of violent and prosocial video game play. Personality and Social Psychology Bulletin, 40, 578 589. http://dx.doi.org/10.1177/0146167213520459

Greitemeyer, T., \& Osswald, S. (2009). Prosocial video games reduce aggressive cognitions. Journal of Experimental Social Psychology, 45, 896-900. http://dx.doi.org/10.1016/j.jesp.2009.04.005

Hart, D., Atkins, R., \& Ford, D. (1998). Urban America as a context for the development of moral identity in adolescence. Journal of Social Issues, 54, 513-530. http://dx.doi.org/10.1111/j.1540-4560.1998.tb01233.x

Hoffman, M. L. (2000). Empathy and moral development: Implications for caring and justice. New York, NY: Cambridge University Press. http:// dx.doi.org/10.1017/CBO9780511805851

Huesmann, L. R., Moise-Titus, J., Podolski, C. L., \& Eron, L. D. (2003). Longitudinal relations between children's exposure to TV violence and their aggressive and violent behavior in young adulthood: 1977-1992. Developmental Psychology, 39, 201-221. http://dx.doi.org/10.1037/ 0012-1649.39.2.201

Krahé, B., Busching, R., \& Möller, I. (2012). Media violence use and aggression among German adolescents: Associations and trajectories of change in a three-wave longitudinal study. Psychology of Popular Media Culture, 1, 152-166. http://dx.doi.org/10.1037/a0028663

Laible, D. J., Carlo, G., \& Roesch, S. C. (2004). Pathways to self-esteem in late adolescence: The role of parent and peer attachment, empathy, and social behaviours. Journal of Adolescence, 27, 703-716. http://dx .doi.org/10.1016/j.adolescence.2004.05.005

Laible, D., McGinley, M., Carlo, G., Augustine, M., \& Murphy, T. (2014). Does engaging in prosocial behavior make children see the world through rose-colored glasses? Developmental Psychology, 50, 872-880. http://dx.doi.org/10.1037/a0033905

Lee, B. (1988). Prosocial content on prime-time television. Applied Social Psychology Annual, 8, 238-246.

Mann, F. D., Kretsch, N., Tackett, J. L., Harden, K. P., \& Tucker-Drob, E. M. (2015). Person $\times$ environment interactions on adolescent delinquency: Sensation seeking, peer deviance and parental monitoring. Personality and Individual Differences, 76, 129-134. http://dx.doi.org/ 10.1016/j.paid.2014.11.055

Mares, M., \& Woodard, E. (2005). Positive effects of television on children's social interactions: A meta-analysis. Media Psychology, 7, 301322. http://dx.doi.org/10.1207/S1532785XMEP0703_4

Moilanen, K. L., Shaw, D. S., \& Fitzpatrick, A. (2010). Self-regulation in early adolescence: Relations with mother-son relationship quality and 
maternal regulatory support and antagonism. Journal of Youth and Adolescence, 39, 1357-1367. http://dx.doi.org/10.1007/s10964-0099485-x

Monahan, K. C., Steinberg, L., Cauffman, E., \& Mulvey, E. P. (2009). Trajectories of antisocial behavior and psychosocial maturity from adolescence to young adulthood. Developmental Psychology, 45, 16541668. http://dx.doi.org/10.1037/a0015862

National Television Violence Study. (1998). Technical report (Vol. 3). Thousand Oaks, CA: Sage.

Novak, S. P., \& Clayton, R. R. (2001). The influence of school environment and self-regulation on transitions between stages of cigarette smoking: A multilevel analysis. Health Psychology, 20, 196-207. http:// dx.doi.org/10.1037/0278-6133.20.3.196

Padilla-Walker, L. M. (2014). Parental socialization of prosocial behavior: A multidimensional approach. In L. M. Padilla-Walker and G. Carlo (Eds.), Prosocial behavior: A multidimensional approach (pp. 131155). New York, NY: Oxford University Press.

Padilla-Walker, L. M., Carlo, G., \& Nielson, M. G. (in press). Does helping keep teens protected? Longitudinal bidirectional relations between prosocial behavior and problem behavior. Child Development.

Padilla-Walker, L. M., \& Christensen, K. J. (2011). Empathy and selfregulation as mediators between parenting and adolescents' prosocial behavior toward strangers, friends, and family. Journal of Research on Adolescence, 21, 545-551. http://dx.doi.org/10.1111/j.1532-7795.2010 .00695.x

Padilla-Walker, L. M., \& Coyne, S. M. (2011). "Turn that thing off!" parent and adolescent predictors of proactive media monitoring. Journal of Adolescence, 34, 705-715. http://dx.doi.org/10.1016/j.adolescence .2010.09.002

Padilla-Walker, L. M., Coyne, S. M., Fraser, A., \& Stockdale, L. (2013). Is Disney the nicest place on earth? A content analysis of prosocial behavior in Disney films. Journal of Communication, 63, 393-412. http://dx .doi.org/10.1111/jcom.12022

Padilla-Walker, L. M., \& Fraser, A. M. (2014). How much is it going to cost me? Bidirectional relations between adolescents' moral personality and prosocial behavior. Journal of Adolescence, 37, 993-1001. http:// dx.doi.org/10.1016/j.adolescence.2014.07.008

Padilla-Walker, L. M., Harper, J. M., \& Bean, R. A., (2011). Pathways to parental knowledge: The role of family process and family structure. Journal of Early Adolescence, 31, 604-627.

Peterson, C., \& Seligman, M. E. P. (2004). Character strengths and virtues: A handbook and classification. Washington, DC: Oxford University Press.
Potter, W., \& Ware, W. (1989). The frequency and context of prosocial acts on primetime TV. The Journalism Quarterly, 66, 359-366. http:// dx.doi.org/10.1177/107769908906600213

Prot, S., Gentile, D. A., Anderson, C. A., Suzuki, K., Swing, E., Lim, K. M., . . Lam, B. C. (2014). Long-term relations among prosocialmedia use, empathy, and prosocial behavior. Psychological Science, 25, 358-368. http://dx.doi.org/10.1177/0956797613503854

Rusbult, C. E., \& Agnew, C. R. (2010). Prosocial motivation and behavior in close relationships. In M. Mikulincer \& P. R. Shaver (Eds.), Prosocial motives, emotions, and behavior: The better angels of our nature (pp. 327-345). Washington, DC: American Psychological Association. http://dx.doi.org/10.1037/12061-017

Saleem, M., Anderson, C. A., \& Gentile, D. A. (2012). Effects of prosocial, neutral, and violent video games on children's helpful and hurtful behaviors. Aggressive Behavior, 38, 281-287. http://dx.doi.org/10.1002/ ab. 21428

Shrout, P. E., \& Fleiss, J. L. (1979). Intraclass correlations: Uses in assessing rater reliability. Psychological Bulletin, 86, 420-428. http:// dx.doi.org/10.1037/0033-2909.86.2.420

Smith, S. W., Smith, S. L., Pieper, K. M., Yoo, J. H., Ferris, A. L., Downs, E., \& Bowden, B. (2006). Altruism on American television: Examining the amount of, and context surrounding, acts of helping and sharing. Journal of Communication, 56, 707-727. http://dx.doi.org/10.1111/j 1460-2466.2006.00316.x

Tabachnick, B. G., \& Fidell, L. S. (2012). Using multivariate statistics (6th ed.). Boston, MA: Pearson.

Weinberger, D. A., \& Schwartz, G. E. (1990). Distress and restraint as superordinate dimensions of self-reported adjustment: A typological perspective. Journal of Personality, 58, 381-417. http://dx.doi.org/ 10.1111/j.1467-6494.1990.tb00235.x

Wentzel, K. R. (1993). Does being good make the grade? Social behavior and academic competence in middle school. Journal of Educational Psychology, 85, 357-364. http://dx.doi.org/10.1037/0022-0663.85.2.357

Williams, L. R., \& Steinberg, L. (2011). Reciprocal relations between parenting and adjustment in a sample of juvenile offenders. Child Development, 82, 633-645. http://dx.doi.org/10.1111/j.1467-8624.2010 .01523.x

Received June 2, 2014

Revision received May 13, 2015

Accepted May 18, 2015 